\title{
EXTREMELYHIGH FERRITIN LEVELS IN A PATIENTWITH MACROPHAGE ACTIVATION SYNDROME ASSOCIATED WITH SYSTEMIC LUPUS ERYTHEMATOSUS
}

Vanessa de Quadros Martins, ${ }^{1, *}$, Deise Marcela Piovesan¹, Bárbara Mendes da Silva1, Marcelo Maltchik¹, Iloite Maria Scheibel², Jean Paulo Veronese de Souza', Roberta Casanova Wilhelms', Camila Schafer ${ }^{1}$, Markus Bredemeier ${ }^{1}$

1. Hospital Nossa Senhora da Conceição, Porto Alegre (RS), Brazil. 2.Hospital da Criança Conceição, Porto Alegre(RS), Brazil.

*Corresponding author: vanessamartinsmed@gmail.com

\section{BACKGROUND}

Hyperferritinemia can be a result of inflammation, infection, chronic iron overload, or other uncommon pathologies, including macrophage activation syndrome (MAS). We herein present a case of severe MAS with an extremely high level of ferritin.

\section{CASE REPORT}

A 25-years-old female patient with systemic lupus erythematosus (SLE) since 2017, with previous history hemolytic anemia and nephritis, attended a medical consultation presenting nodular lesions in both tights (with superficial phlogistic signs) and fever initiated one week before. She was taking chloroquine diphosphate $250 \mathrm{mg}$, mycophenolate mofetil $2 \mathrm{~g}$, prednisone $20 \mathrm{mg}$ and enalapril $20 \mathrm{mg}$ every day. She was sent to the emergency department, and lab evaluation demonstrated pancytopenia (hemoglobin, 9.0 mg/dL; leukocytes, 2020; segmented neutrophils, 1505; lymphocytes, 101; platelets, 79,000), acute renal failure (serum urea, $219 \mathrm{mg} / \mathrm{dL}$; creatinine, $3.48 \mathrm{mg} / \mathrm{dL}$; potassium, $7.1 \mathrm{mEq} / \mathrm{L}$ ), hepatic disfunction [aspartate aminotransferase (AST), $218 \mathrm{U} / \mathrm{L}$; alanine-aminotransferase (ALT), $55 \mathrm{U} / \mathrm{L}$; gamma-glutamyltransferase (GGT), $1093 \mathrm{U} / \mathrm{L}$; alkaline phosphatase, $712 \mathrm{U} / \mathrm{L}$; total bilirubin, $3.21 \mathrm{mg} / \mathrm{dL}$; albumin, 2,0 g/dL; lactate dehydrogenase (LDH), $2622 \mathrm{U} / \mathrm{L}$ ]. Vital signs were normal. Empirical antibiotic coverage was started and the use of mycophenolate was interrupted. Intravenous methylprednisolone was prescribed at the dose of $60 \mathrm{mg} / \mathrm{day}$. After $48 \mathrm{~h}$ of treatment, the patient presented copious melena and worsened neutropenia $(790$ segmented neutrophils and undetected lymphocytes). Upper endoscopy demonstrated multiple Cameron lesions, with negative search for cytomegalovirus (by biopsy and PCR). Considering the diagnosis of MAS, intravenous hyperimmune immunoglobulin (IVHI) was infused over 5 days $(400 \mathrm{mg} / \mathrm{kg} /$ day). Hemodialysis was initiated due to acidosis and hyperkalemia refractory to clinical management. There was no apparent response to IVHI, and worsening of laboratory exams was observed (ferritin $>100,000 \mathrm{ng} / \mathrm{mL}$; fibrinogen, $79 \mathrm{mg} / \mathrm{dL}$; AST, $931 \mathrm{U} / \mathrm{L} ;$ ALT, $155 \mathrm{U} / \mathrm{L}$; triglycerides, $186 \mathrm{mg} / \mathrm{dL}$; LDH, $9590 \mathrm{U} / \mathrm{L}$ ). Pulse steroid dose (1000 mg/day of methylprednisolone for 3 days) and oral cyclosporin (up to $3 \mathrm{mg} / \mathrm{kg}$ ) were added to the treatment. Bone marrow biopsy showed medullary hemophagocytosis. Ferritin remained in extremely high levels in 2 dosages (>100,000 and equal to $90,069 \mathrm{ng} / \mathrm{mL}$ ) over the next 3 days. Nine days after admission to the hospital room, the patient presented multiple bleeding sites (digestive, insertion of catheters, and biopsy wound) leading to hemodynamic instability. Etoposide treatment was indicated, but patient evolved with multiple organ failure and death.

\section{CONCLUSION}

We report here a case of extreme hyperferritinemia in MAS related to SLE. Reports of such high levels of ferritin are unusual, and are associated with poor clinical outcome. 